\title{
INCLUSÃO NO ATENDIMENTO EDUCACIONAL ESPECIALIZADO NA EDUCAÇÃO BÁSICA: Um Estudo de Caso
}

\author{
Cleusa Inês Ziesmann ${ }^{1}$ \\ Alexandre Anselmo Guilherme ${ }^{2}$
}

\begin{abstract}
RESUMO
Este estudo tem como problemática principal compreender como os professores do município de Santa Rosa (RS), que trabalham nas salas de Atendimento Educacional Especializado (AEE) e nas salas do ensino regular, entendem e efetivam a inclusão no espaço escolar. Para o método emprega-se a pesquisa bibliográfica, complementada pela pesquisa de campo na modalidade qualitativa. A realização da coleta de dados aconteceu por meio de observações em salas de aula e salas do atendimento educacional especializado, em duas escolas municipais que possuem o atendimento, e entrevistas semiestruturadas, envolvendo professores da sala de aula do ensino regular, educadoras do atendimento educacional especializado e monitoras que auxiliam no processo de inclusão das crianças nessas escolas. A análise desse material foi embasada pelos pressupostos de Bardin (2011), com a Análise de Conteúdo. A vivência nesses espaços de compartilhamentos permitiu compreender que a inclusão é um processo que não pode ter práticas isoladas, e todos necessitam estar dispostos a irem na mesma direção ou em busca de um mesmo objetivo. Os profissionais necessitam ter clareza das ações ainda recorrentes nesse processo.
\end{abstract}

Palavras-chave: Educação inclusiva. Atendimento educacional especializado. Ensino regular. Formação docente.

\section{INCLUSION IN EDUCATIONAL CARE SPECIALIZED IN PRIMARY SCHOOL EDUCATION: A CASE STUDY}

\begin{abstract}
This study has as main problem to understand how the teachers of the city of Santa Rosa (RS), who work in the Specialized Educational Attendance rooms (SEA) and in the classrooms of mainstream education, understand and effect the inclusion in the space school. For the method, we employ the bibliographic research complemented by field research in qualitative modalities. The realization of data collection happened through observations in two Municipal Schools that possess the SEA and semi-structured interviews, involving teachers from the classroom of mainstream education, SEA educators and monitors that assist in the process of inclusion of children in these schools. The analysis of this material was based on Bardin's assumptions (2011) with Content Analysis. The experience in these sharing spaces allowed us to understand that inclusion is a process that cannot have isolated practices, but that everyone needs to be willing to go in the same direction or in search of the same goal, and that the professionals need have clarity of the still recurring actions in this process.
\end{abstract}

Keywords: Inclusive education. Specialized educational service. Regular teaching. Teacher education.

RECEBIDO EM: 31/5/2019

ACEITO EM: 29/10/2019

\footnotetext{
${ }^{1}$ Doutora em Educação pela Pontifícia Universidade Católica do Rio Grande do Sul (PUCRS). Mestre em Educação nas Ciências pela Universidade Regional do Noroeste do Estado do Rio Grande do Sul (Unijuí). Especialista em Interpretação, Tradução e Docência de Língua Brasileira de Sinais (Uníntese). Especialista em Psicopedagogia Institucional pela Faculdade de Ciências Sociais Aplicadas (Facisa). Graduada em Pedagogia - Orientação e Supervisão Escolar (Unijuí). Professora na Universidade Federal da Fronteira Sul/campus Cerro Largo/RS. É membro do Grupo de Pesquisa de Estudos e Pesquisa Educação e Violência (Grupev - PUCRS), do Grupo de Pesquisa Gepetec e do Grupo de Estudos e Pesquisa Direitos Humanos, Movimentos e Instituições da UFFS de Cerro Largo/RS. Atua na área de Educação com ênfase em Educação Especial/Inclusiva, Língua Brasileira de Sinais, Atendimento Educacional Especializado e Formação de Professores. http:// buscatextual.cnpq.br/buscatextual/visualizacv.do?id=K4323833A4.http://orcid.org/0000-0001-7114-5432. cleusa.ziesmann@uffs.edu.br

${ }^{2}$ Graduação MA Honours em Filosofia (University of Edinburgh, 2001). Mestrado MLitt em Filosofia (University of St Andrews, 2002). Doutorado PhD em Filosofia (Durham University, 2008). Pós-Doutorado pelo Institute of Advanced Studies in Humanity, University of Edinburgh (2010). Professor-adjunto do PPGEdu e do PPGP da PUCRS, atuando principalmente nos seguintes temas: educação e violência e educação e diálogo. Editor-associado da Revista Educação-PUCRS. Membro editorial da Revista Philosophy and Theory in Higher Education. Coordenador de Projeto para o Programa Institucional Capes-PrInt. http://buscatextual.cnpq.br/buscatextual/visualizacv. do?id=K4365355A6. http://orcid.org/0000-0003-4578-1894.
} 
Neste artigo apresentamos um recorte de uma pesquisa de Doutorado que trata do atendimento educacional especializado na educação básica na perspectiva da teoria histórico-cultural. Atualmente, a legislação vigente no Brasil assegura o acesso à Educação Básica a todas as crianças e jovens. A abertura das escolas em relação ao seu espaço arquitetônico e organizacional, contudo, não veio acompanhada de transformações capazes de auxiliar suficientemente as transformações das formas de organização, funcionamento e gestão do ensino e da aprendizagem, especialmente quando se trata da inclusão de estudantes com deficiência nas salas do ensino regular. Pode-se afirmar, inclusive, que a ideia de inclusão educacional, que está regulamentada em leis e em propostas de políticas públicas, está longe de se concretizar em práticas educativas no interior dos sistemas de ensino. Assim, os estudos sobre Educação Inclusiva e o Atendimento Educacional Especializado, especificamente sobre a escolarização dos estudantes com deficiência intelectual, auditiva, visual, física e múltipla, transtornos globais de desenvolvimento e altas habilidades (superdotados), tornam-se indispensáveis e configuram-se em mudança nas concepções e nas práticas pedagógicas nas Instituições de Ensino.

Segundo Stainback e Stainback (1999, p. 21), "a educação inclusiva pode ser definida como a prática da inclusão de todos, independentemente de seu talento, deficiência, origem socioeconômica ou cultural em escolas e salas de aula provedoras, em que as necessidades desses alunos sejam satisfeitas." A Educação Inclusiva, porém, somente irá acontecer em um meio escolar que aceite e respeite as necessidades de cada um de forma análoga.

Sobre a Educação Inclusiva, Mendes (2002) assevera:

A educação inclusiva é uma proposta de aplicação prática ao campo da educação de um movimento mundial, denominado de inclusão social, o qual é proposto como um novo paradigma e implica a construção de um processo bilateral no qual as pessoas excluídas e a sociedade buscam, em parceria, efetivar a equiparação de oportunidades para todos (p. 61).

Pesquisas recentes sobre a temática, como a de Marques (2007), Fogli (2010) e Fiorini (2011), têm o propósito de apresentar as necessidades e possibilidades de efetivação desse processo de educação a fim de atender efetivamente os alunos em todos os níveis de ensino. Para uma melhor compreensão, passa-se a apresentar um pequeno marco legal e pedagógico para entender, com mais clareza, a proposta da inclusão escolar, bem como apresentamos a proposta do atendimento educacional especializado na educação básica.

Segundo Mendes (2002),

A ideia da inclusão se fundamenta numa filosofia que reconhece e aceita a diversidade na vida em sociedade. Isto significa garantia de acesso de todos a todas as oportunidades, independentemente das peculiaridades de cada indivíduo no grupo social (p. 28).

A inclusão, porém, não pode ser vista como uma proposta de algo que se almeja ou um lugar onde se quer chegar, tampouco pode ser resumida em uma simples inserção em sala de aula. A inclusão vai muito além dessa simples inserção em um espaço institucional, pois é um processo que, nas palavras de Fogli (2010, p. 25), "reitera prin- 
cípios democráticos de participação social plena e não se resume, portanto, a um ou alguns setores da vida, como saúde, lazer ou educação". Trata-se de uma luta, de um movimento, que se caracteriza por estar presente nas áreas da vida humana, inclusive na educacional. Tal afirmação corrobora o que traz Carvalho (2006), afirmando que um dos propósitos das escolas seria pautar na aprendizagem coletiva, para que se possa reconhecer, identificar e considerar as diferenças e dificuldades de cada aluno, oferecendo a cada um, dentro dos limites de suas potencialidades, instrumentos pedagógicos capazes de auxiliá-lo na superação dessas suas dificuldades.

Nessa linha de pensamento, apresentamos resultados de um estudo que procurou analisar as concepções dos professores sobre a inclusão e a forma como essas concepções podem afetar diretamente os estudantes no seu processo de aprendizagem no Atendimento Educacional Especializado de duas escolas do município de Santa Rosa (RS). O estudo deu-se por intermédio de um projeto de pesquisa desenvolvido em duas escolas de Santa Rosa, com a intencionalidade de criar e analisar espaços coletivos de estudo e discussão sobre a Educação Inclusiva e o Atendimento Educacional Especializado (AEE) nas instituições do ensino regular. As escolas, no decorrer de nosso texto, estão denominadas como Escola 1 e Escola 2. A investigação foi desenvolvida no período de abril a outubro de 2018 com a realização de encontros semanais, nos quais foram desenvolvidas atividades de observação dos espaços do Atendimento Educacional Especializado, da sala de aula e do entorno da escola.

Considerando que a produção de conhecimentos e a constante formação sobre a educação inclusiva, bem como sobre o Atendimento Educacional Especializado nas escolas de ensino regular é ainda algo necessário a se efetivar em todas as situações no espaço escolar, o presente estudo foi orientado pela seguinte questão: Como os professores do município de Santa Rosa (RS), que trabalham nas salas de Atendimento Educacional Especializado e nas salas do ensino regular, entendem e efetivam a inclusão no espaço escolar?

Para o método emprega-se a pesquisa bibliográfica complementada pela pesquisa de campo qualitativa, pois possibilita investigar um fenômeno contemporâneo dentro de um contexto da vida real. Já a abordagem qualitativa justifica-se na medida em que [...] trabalha com o universo de significados, motivos, aspirações, crenças, valores e atitudes, o que corresponde a um espaço mais profundo das relações, dos processos e dos fenômenos que não podem ser reduzidos à operacionalização de variáveis (MINAYO, 1999, p. 22).

Os dados desta investigação foram produzidos a partir das observações registradas em um diário de bordo com o objetivo de registrar todos os momentos das observações, bem como as reações que, porventura, pudessem ser esquecidas para a análise e, ainda, com gravações em áudio dos encontros realizados com os sujeitos participantes durante as entrevistas semiestruturadas. Posteriormente, todo o material foi transcrito e analisado. A organização desses dados, coletados durante todo esse período, foi feito com base nos argumentos de Bardin (2011) na perspectiva da Análise de Conteúdo, o que permitiu apresentar categorias emergentes aqui discriminadas como: "Os desafios 
da Educação Inclusiva: os marcos legais e seus significados sociais", "As concepções e disputas do modelo clínico e social sobre a educação de pessoas com deficiência" e "O atendimento educacional especializado nas escolas de educação básica".

Para analisar os dados produzidos buscamos apoio teórico em autores como Mazzotta, Vygotsky, Mantoan, Góes, Carvalho e Mendes, que dialogam sobre a educação inclusiva e o Atendimento Educacional Especializado, e em documentos que tratam da Política Nacional de Educação Especial na perspectiva de Educação Inclusiva que nos apresentam importantes contribuições sobre a educação escolar para crianças com deficiência. Para preservarmos a identidade dos profissionais participantes de nosso estudo, foram utilizados nomes fictícios: Professora 1, 2, 3, 4 e 5 denominando os professores da sala regular, Educadoras Especiais 1, 2, e 3 para as educadoras especiais que atuam nas salas de atendimento educacional especializado ou salas multifuncionais e, ainda, Monitoras 1, 2, 3 e 4 para as monitoras que atuam nas salas do ensino regular das duas escolas escolhidas para a realização da investigação. Ressalta-se que toda a pesquisa está amparada e em consonância com as diretrizes da Resolução n. 510, de 7 de abril de 2016, do Conselho Nacional de Saúde (CNS).

\section{OS DESAFIOS DA EDUCAÇÃO INCLUSIVA: Os Marcos Legais e Seus Significados Sociais}

No Reino Unido, na década de 60, um grupo de pessoas organizou um movimento chamado Social Disability Movement, com o objetivo de mostrar à sociedade que grande parte das dificuldades enfrentadas pelo sujeito com deficiência é o modo como é visto e tratado em relação às suas limitações e/ou necessidades. Esse grupo teve a iniciativa de propor estudos que visaram à conscientização dos processos discriminatórios que vinham rotulando os sujeitos com deficiência. O modelo social de educação procurava provocar uma mudança de postura e uma nova compreensão sobre a inclusão por parte dos gestores, da mídia, da família e dos profissionais da educação, compreendendo-a como algo resultante de uma diversidade que existia e que existe nos dias atuais na sociedade.

A primeira referência sobre a Educação Especial no Brasil data do período Imperial, quando Dom Pedro II, no ano de 1854, com forte influência do médico da Família Imperial, o senhor José Xavier Sigaud, participou da criação da Sociedade de Medicina no Rio de Janeiro. José Álvares de Azevedo, um jovem cego, ministrava aulas de braile para a filha de Sigaud, e incentivou a fundação do então Imperial Instituto dos Meninos Cegos, que tinha por atribuição ministrar aulas em nível primário e depois secundário, de música, educação moral e religiosa, bem como o ofício do trabalho para meninos. Já a partir de 1891, essa instituição de ensino passou a ser chamada de Instituto Benjamin Constant (IBC), conhecido hoje pelo trabalho comprometido com a educação para pessoas cegas (BUENO, 1993; MAZZOTTA, 1993).

Durante o reinado de Dom Pedro II no ano de 1855, a vinda do francês Hernest Huet para o Brasil, a pedido do rei, teve a intenção de criar uma escola para ensinar os surdos-mudos. Huet, professor surdo, com Mestrado e diversos cursos realizados em Paris, era, na opinião do rei, a pessoa ideal para o atendimento de crianças e jovens surdos. Dessa forma, no ano de 1857 foi fundada a primeira escola para surdos no Rio de 
Janeiro, o chamado Imperial Instituto dos Surdos-Mudos (ROCHA, 1997). O Instituto foi criado pela Lei n. 939, de 26 de setembro de 1857; atendia meninos surdos que vinham de todo o Brasil e funcionava na modalidade de internato.

Em 1872, conforme estudos realizados por Soares (1999), o então Imperial Instituto dos Meninos Cegos atendia em média 35 alunos cegos, e, desses, 20 pagavam pelos seus estudos, pois eram oriundos de famílias mais abastadas. De acordo com Mazzotta (1996), nesse período havia em torno de 15.848 pessoas com deficiência visual no Brasil que ainda não recebiam atendimento em instituições de ensino. Até o ano de 1926, quando foi fundado o Instituto São Rafael, em Belo Horizonte, os deficientes visuais e cegos no Brasil somente tinham atendimento no Instituto Benjamim Constant, por ser a única instituição especializada nesse atendimento.

A partir de então, foram surgindo outras instituições de ensino com caráter ainda muito segregacionista. Em 1927 foi fundado, em São Paulo, o Instituto para Cegos "Padre Chico" e, em Porto Alegre, o Instituto Santa Luzia; em 1935, em Pernambuco, o Instituto dos Cegos; em 1936, em Salvador, o Instituto de Cegos na Bahia; e, em 1944, em Curitiba, o Instituto Paranaense dos Cegos (BUENO, 1993; MAZZOTTA, 1996).

De acordo com Rocha (1997), os surdos eram preparados para o mercado de trabalho pesado e para comunicar-se na época com gestos. As meninas iniciaram suas atividades escolares nesse Instituto a partir do ano de 1931, e eram inseridas nas oficinas de corte, costura e bordado. Com o passar dos anos, muitas lideranças surdas surgiram, retornando para suas cidades e empreendendo o estudo da Língua de Sinais e a sua difusão com a fundação de associações e escolas em prol dos direitos dos sujeitos surdos.

No ano de 1945, em São Paulo, foi inaugurado o primeiro curso de especialização de professores para o ensino de pessoas com deficiência visual no Instituto de Educação Caetano de Campos. Em 1946, a Fundação para o Livro do Cego no Brasil iniciou um processo de impressão de materiais em braile. Atualmente, essa Fundação é denominada Fundação Dorina Nowill para Cegos e possibilita às pessoas cegas melhores condições de estudo, com a publicação de diversos materiais em braile (BUENO, 1993; MAZZOTTA, 1996).

Nessa época, o sujeito surdo era considerado sem direitos, pois era desprovido de capacidades, e, sem conseguir pensar, encontrava-se no mesmo patamar das mulheres e escravos (MOURA, 1997). Para piorar o caso do surdo, ele ainda não falava, ficando à margem de uma sociedade que priorizava os discursos, os pensamentos e as condições de abstrair informações. Durante esse período, a maioria dos surdos precisava aprender a falar para ser reconhecida como ser humano. Por volta do século 14 , contudo, 0 filósofo e médico Girolamo Cardano (1501-1576) já havia reconhecido a habilidade dos surdos para a razão e, para tanto, fazia uso da língua de sinais e da escrita com estes.

Nessa perspectiva de entendimento, Sacks (1998) adverte que

É possível dar a um surdo-mudo condições de ouvir pela leitura e de falar pela escrita [...], pois assim como diferentes sons são usados convencionalmente para significar coisas diferentes, também podem ter essa função as diversas figuras de objetos e palavras. [...] Caracteres escritos e ideias podem ser conectados sem a intervenção de sons verdadeiros (p. 29). 
Muitas outras discussões acerca da educação de surdos, naquele período, geraram inquietações sobre o seu ensino em todo o território mundial. Em 1760, Charles-Michel de L'Epée aproximou-se dos surdos para aprender a Língua de Sinais Francesa com objetivos religiosos, pois os surdos ainda eram condenados pela Igreja como castigo. Sem direito à profissão de fé, os surdos não tinham como seguir os ensinamentos do catolicismo por não conhecê-los. No Brasil, a mistura da Língua de Sinais Francesa com o que os surdos já usavam por aqui para se comunicar entre seus pares, facilitou o surgimento da Língua Brasileira de Sinais (Libras). Essa língua foi oficializada no Brasil pela Lei n. 10.436, de 24 de abril de 2002, regulamentada pelo Decreto n. 5.626, de 22 de dezembro de 2005. Depois de conhecer a Língua de Sinais, L'Epée a usou para instruir os surdos na fé e também em conhecimentos escolares. De acordo com Sacks (1998, p. 30), "[...] e então, associando sinais a figuras e palavras escritas, o abade ensinou-os a ler; e com isso, de um golpe, deu-lhes o acesso aos conhecimentos e à cultura do mundo." Já o atendimento de deficientes mentais, ${ }^{3}$ a partir de 1874, era realizado no hospital psiquiátrico da Bahia, hoje conhecido como Hospital Juliano Moreira. Como a deficiência intelectual era considerada um problema orgânico, muitos temiam que ela pudesse gerar o fracasso escolar nas escolas, ganhando destaque nas políticas públicas após a Proclamação da República (PESSOTTI, 1984). Com isso, por volta de 1930, surgiram inúmeras instituições de ensino para cuidar da deficiência intelectual em uma escala muito maior, considerando também as outras deficiências.

Pessotti (1984), em seus estudos, apresenta uma historicidade sobre a Educação Especial para pessoas com deficiência e registra diferentes formas de perceber esses sujeitos. No ano de 1926 foi fundado o Instituto Pestalozzi, ${ }^{4}$ especializado em atendimento às pessoas com deficiência intelectual. Em 1945, Helena Wladimirna Antipoff realizou os primeiros atendimentos educacionais especializados aos sujeitos com superdotação na Sociedade Pestalozzi. De origem russa, essa protagonista da história deflagrou sobre a ascensão da deficiência intelectual, atuando como psicóloga e pedagoga que, em 1929, após obter formação universitária na Rússia, Paris e Genebra, fixou-se no Brasil, onde dedicou seus estudos aos atendimentos de crianças com deficiência. Foi pioneira nos estudos relacionados à Educação Especial no Brasil, fundando a primeira Sociedade Pestalozzi.

Por volta de 1954 a 1962, surgiram as Associações de Pais e Amigos dos Excepcionais (Apaes) no Brasil. Essas organizações filantrópicas discutiam a questão da pessoa com deficiência, a melhoria da sua qualidade de vida e a conscientização da sociedade. No dia 10 de novembro de 1962 foi fundada a Federação Nacional das Apaes em São Paulo, no consultório de Stanislau Krynsky, local usado como sede das reuniões até esta data (ARANHA, 2001).

\footnotetext{
3 Em 1995 a Organização das Nações Unidas (ONU) alterou o termo "deficiência mental" para "deficiência intelectual", com o objetivo de diferenciá-la da doença mental (transtornos mentais que não necessariamente estão associados ao déficit intelectual).

${ }^{4}$ A primeira escola, com o nome "Pestalozzi", foi criada em Canoas, no Rio Grande do Sul, em 1927. Helena Wladimirna Antipoff influenciou na ampliação da rede das Sociedades e Institutos em âmbito nacional, principalmente com o apoio de Francisco Campos, secretário de Educação de Minas Gerais que, posteriormente, se tornou ministro da Educação (PEREIRA, 2016).
} 
Com o surgimento das Apaes no atendimento das pessoas com deficiência intelectual, ${ }^{5}$ cresceu o número de filantropias e assistencialismo. Essas instituições, que eram totalmente privadas, tiveram um destaque maior no panorama da Educação Especial Brasileira, considerando os atendimentos realizados pelas instituições públicas, que foram enfraquecidas junto as instâncias superiores para participar de discussões sobre assuntos relacionados à educação.

Ao mesmo tempo, surgiu a necessidade de escolarização desses sujeitos, pois, até então, a sociedade via o deficiente como um indivíduo que não poderia conviver com os outros em razão das suas limitações e dificuldades, necessitando estudar em locais separados ou até mesmo em locais isolados. A sua aceitação na sociedade somente aconteceu a partir do momento em que puderam comprovar que estavam mais próximos da normalidade estipulada pela sociedade da época. Esse momento, efetivamente, foi marcado pelo surgimento da Psicologia voltada à educação dos sujeitos com deficiência e das classes especiais.

Mesmo com pesquisas apontando vários resultados favoráveis sobre a aprendizagem de sujeitos com deficiência, ainda existem dúvidas por parte de vários profissionais da área. Lino de Paula (1994, p. 5) enfatiza que essa percepção está enraizada na sociedade, e afirma que "justifica-se assim, a discriminação, a segregação, a exclusão do conjunto da sociedade, a legitimidade do controle exercido por um sujeito racional e a eterna recorrência à tutela e à caridade pública."

De certa forma, se for observada a legislação, percebe-se que na Lei de Diretrizes e Bases da Educação (BRASIL, 1996) sobre o direito dos excepcionais ${ }^{6}$ à educação, já estava imbuído o interesse pelo atendimento acontecer, preferencialmente, nas escolas da rede regular de ensino. No Título $X$ da referida Lei, em seu artigo 88, no que refere sobre a Educação de Excepcionais, consta que "a educação de excepcionais, deve, no que for possível, enquadrar-se no sistema geral de educação, a fim de integrá-los na comunidade". Da mesma forma, expressa o artigo 89 da mesma Lei ora referida que "toda iniciativa privada considerada eficiente pelos Conselhos Estaduais de Educação, e relativa à educação de excepcionais, receberá dos poderes públicos tratamento especial mediante bolsas de estudo, empréstimos e subvenções".

Pode-se perceber, então, que nos anos 60 e 70 a prática de integração do deficiente estava aliada ao processo de habilitar-se, reabilitar-se ou, ainda, educar-se para se tornar apto a satisfazer um padrão considerado correto ou adequado pela sociedade, pela família e pelas instituições de ensino. Conforme Mantoan (2005), durante a década

\footnotetext{
${ }^{5}$ A pessoa com deficiência intelectual caracteriza-se por ter um funcionamento intelectual significativamente inferior à média, acompanhado de limitações adaptativas significativas em, pelo menos, duas das seguintes áreas de habilidades: comunicação, autocuidados, vida doméstica, habilidades sociais/interpessoais, uso de recursos comunitários, autossuficiência, habilidades acadêmicas, trabalho, lazer, saúde e segurança (SASSAKI, 2002).

6 "Excepcionais" foi o termo utilizado nas décadas de 50, 60 e 70 do século 20, para designar pessoas com deficiência intelectual. Com o surgimento de estudos e práticas educacionais nas décadas de 80 e 90 a respeito de altas habilidades ou talentos extraordinários, o termo excepcionais passou a referir-se tanto a pessoas com inteligências múltiplas acima da média (pessoas superdotadas ou com altas habilidades e gênios) quanto a pessoas com inteligência lógico-matemática abaixo da média (pessoas com deficiência intelectual) (SASSAKI, 2002).
} 
de 70, por todo o mundo Ocidental, houve um amplo movimento sobre a obrigatoriedade da escolaridade, inclusive para os deficientes, o que favoreceu o início de um estudo sobre os serviços que a Educação Especial careceria oferecer.

\section{AS CONCEPÇÕES E DISPUTAS DO MODELO CLÍNICO E SOCIAL SOBRE A EDUCAÇÃO DE PESSOAS COM DEFICIÊNCIA}

A Educação Especial ainda é vista como um espaço fragmentado e especializado da educação. Em determinados casos é marcada pela inserção médico-pedagógica (RAMPELOTTO, 2004 ), com práticas pedagógicas ancoradas em modelos clínicos com uma proposta de normalização. Essa prática de normalização ou de tornar todos iguais, tem como objetivo intervir, de maneira terapêutica, no tratamento e cuidado do corpo e da mente. Skliar e Souza (1999, p. 17), salientam que isso é "consequência de uma tradição histórica de controle do [outro] sujeito deficiente por expertos e aficionados na Medicina".

A partir da compreensão de Skliar e Souza (2000) pode-se perceber que a Educação Especial ainda preserva "para si um olhar iluminista sobre a identidade de seus sujeitos". Dessa forma, ela constitui algo "perfeito/imperfeito, normalidade/anormalidade, de racionalidade/irracionalidade e de completude/incompletude como elementos centrais na produção e práticas pedagógicas" (2000, p. 269). Os pesquisadores supramencionados enfatizam que, na Educação Especial, "os sujeitos [outros] são homogeneizados e naturalizados, valendo-se de representações sobre aquilo que está faltando em seus corpos, em suas mentes e em sua linguagem" (2000, p. 269).

A partir do ano de 1854, a história da educação de pessoas com deficiência no Brasil foi marcada por iniciativas de caráter muito privado, especialmente questões quanto ao atendimento médico/clínico especializado. Nesse período da história brasileira, também surgiram instituições com atendimento tradicional com vistas ao atendimento assistencialista e segregacionista às pessoas com deficiência.

Estudos realizados por Sassaki (2002) no início da década de 70, revelam que um movimento sobre a integração social passou a ser alvo de intensas discussões, pois tratava da intenção de ampliar a inserção do deficiente na sociedade. Foi, porém, somente a partir da década de 80 que, de um modo geral, com o amplo surgimento de discussões sobre o tema, a prática de integrar a pessoa com deficiência realmente efetivou-se em alguns setores, mais especificamente nas Instituições de Ensino. Ao relacionar o caso com os sujeitos com deficiência da atualidade, percebe-se que isso ainda acontece, pois muitos pesquisadores olham apenas para a deficiência/patologia, pensando em uma incapacidade ou em uma desvantagem, limitando um olhar clínico/médico/biomédico da deficiência (BATISTA, 2006).

Esse Modelo Clínico/Médico/Biomédico compreende a deficiência como um fenômeno biológico, cuja concepção a trata como uma lesão no corpo adquirida por meio de uma doença (DINIZ, 2003). Assim, a deficiência é percebida como uma incapacidade física, uma doença que leva esses indivíduos a possuírem uma série de desvantagens se comparados aos sujeitos sem deficiência. O Modelo Social de inclusão surgiu nos anos 60, no Reino Unido, "e provocou reviravolta nos modelos tradicionais de compreensão da deficiência ao retirar do indivíduo a origem da desigualdade, experimentada pelos 
deficientes, e devolvê-la à sociedade" (BAMPI; GUILHEM; ALVES, 2010, p. 6). O modelo é considerado "uma corrente teórica e política que se contrapõe ao modelo médico dominante" (p. 6).

O sociólogo Hunt (1966), ao argumentar sobre as limitações sociais para além das questões médicas, elaborou a primeira publicação com o auxílio de pessoas com deficiência. Na Inglaterra, Hunt também foi o pioneiro em articulações políticas em prol de um movimento a favor das pessoas com deficiência (BARNES; MENCER, 1996). A partir dessas interlocuções, surgiu, em 1976, a Union of the Physically Imapired Against Segregation (Upias), uma entidade de natureza social, responsável por uma nova concepção de deficiência.

Conforme a Upias, o Modelo Social é um instrumento essencialmente político para a interpretação da realidade com fins de transformação social. França (2013), em seus estudos, ressalta que o mesmo desconsidera qualquer tipo de relação entre deficiência e saúde. O autor ressalta que "a deficiência independe da lesão física, mesmo sendo condição necessária para a manifestação da deficiência" (p. 63). Com base nessas afirmações, pode-se assegurar que, a partir de Vygotsky (2002, p. 153), "[...] a cultura pode criar condições para desfazer as diferenças de capacidades. $\mathrm{O}$ desenvolvimento cultural desfaz ou, falando com mais exatidão, torna histórico o caráter natural da insuficiência orgânica".

Nessa mesma perspectiva, estudos realizados por Werneck (2004, p. 16-20) mostram algumas proposições referentes às principais diferenças descritas entre o modelo clínico e social sobre a deficiência. A partir de tais proposições, apresentadas por Werneck (2004), é possível compreender o Modelo Social de inclusão na educação como um assunto ainda a ser estudado pela comunidade escolar, alterando significativamente a compreensão da maioria dos sujeitos sobre a deficiência e a diversidade. Percebe-se, porém, que este não apenas concebe o ser humano de forma isolada ou individualizada para se inserir num padrão de normalidade, exigida por uma sociedade exclusivista, nas também como alguém em processo de relação com o outro e consigo mesmo, participando de um grupo social, constituindo-se a partir de relações com o outro (PAULA, 2004).

Izquierdo (2006) relata em seus estudos que, de acordo o Warnock Report, ${ }^{7}$ o diagnóstico, que até então preconizava uma visão médica, foi muito contestado e substituído por um modelo que valorizasse a questão educacional como forma de integrar a criança com deficiência nas escolas do ensino regular bem como na sociedade. $O$ que se percebe, porém, a partir do Warnock Report e da Declaração de Salamanca, é que se inicia um novo período de transição na educação. Assim, a integração, que até então vinha sendo defendida, não era suficiente para que o sujeito tivesse acesso e direito à permanência na escola.

Trata-se de um relatório britânico publicado na Inglaterra em 1978, realizado e organizado por uma comissão dirigida por Helen Mary Warnock, encarregada de elaborar propostas para a melhoria no atendimento a crianças com deficiência. Helen Mary Warnock, nascida no dia 14 de abril de 1924, é membro da Academia Britânica, filósofa britânica, especialista em Filosofia Moral, Filosofia da Educação e Filosofia da Mente, estudiosa do existencialismo. Ela presidiu a comissão britânica sobre Educação Especial (1974-1978), resultando no Warnock Report. 
Depois de aproximadamente 25 anos da publicação do Relatório Warnock, houve uma extensa e variada produção acadêmica em relação à questão da Educação Inclusiva em termos de significado, aplicação e desafios futuros, tanto referindo-se à política quanto à prática. Paula (2004) relata que o legado mais desastroso do Relatório trata do conceito de inclusão que hoje, notoriamente, é interpretado de maneira totalmente errônea.

A autora infere que a falta de reconhecimento das diferenças significativas decorre da confusão de que a inclusão é específica aos indivíduos categorizados ou com necessidades especiais. Inclusão, na visão de Frederick (2005, p. 19), não se refere somente a pessoas com deficiência, mas vai muito além, e a "[...] inclusão significa lutar contra racismo, homofobia e bullying. É uma questão de toda a escola [...]" e, como tal, está relacionada à diversidade existente na escola, bem como às formas de discriminação e exclusão. Na verdade, o autor ressalta que inclusão é perceber o sujeito no seu bem-estar, enfim, no bem-estar dos seres humanos.

Em seus estudos, Vygotsky (2008, p. 3) discorre sobre a questão das diferenças existentes nos seres humanos e da necessidade de preservar o que a criança apresenta. Dessa forma, muitas vezes atribui-se certas ações compensatórias às crianças com deficiência. Essas compensações são compreendidas como "um processo fundamental do desenvolvimento do indivíduo com deficiência" e se faz presente em qualquer pessoa que pertença a certo grupo com relações sociais.

Para Góes (1996), no ser humano "ocorrem compensações de ordem orgânica, pelas quais um órgão substitui o outro, ou realiza as funções deste. Não obstante, para compreender o funcionamento humano, é essencial considerar as compensações sociopsicológicas". De acordo com a autora, as relações estabelecidas com o outro são de troca, e promovem a interação e o desenvolvimento do ser humano.

\section{O ATENDIMENTO EDUCACIONAL ESPECIALIZADO NAS ESCOLAS DE EDUCAÇÃO BÁSICA}

Questões sobre a inclusão escolar cada vez mais estão presentes nos discursos e políticas educacionais nesses últimos anos e, em virtude disso, há necessidade da efetivação de ações inclusivas no contexto escolar para atendimento das crianças com dificuldades de aprendizagem e com deficiência. A Política Nacional de Educação Especial na Perspectiva da Educação Inclusiva (BRASIL, 2008), assegura o direito de toda criança frequentar a escola do ensino comum e, ainda, apresenta, de forma muito clara, as ações que são de competência da educação especial e aquelas que são de competência do ensino comum.

O documento, assim como já indicava o texto do Warnock Report, expressa que o ensino comum, ou a escola regular, tem a responsabilidade da escolarização dos alunos, indistintamente, nas classes comuns de ensino. Já a Educação Especial, modalidade que perpassa todos os níveis de ensino, é responsável por atender os alunos que apresentam deficiência, transtornos globais de desenvolvimento, altas habilidades e/ ou superdotação. Dentre esses serviços, o documento orienta sobre a necessidade de organização da oferta do Atendimento Educacional Especializado. Essa política assegu- 
ra, portanto, que os alunos aprendam de acordo com os estímulos necessários e, ainda, segundo as suas condições e ritmo de aprendizagem, necessários para ultrapassar as barreiras impostas pela dificuldade que apresentam ou por sua deficiência.

A Conferência Mundial de Educação, que aconteceu em 1994 na cidade de Salamanca, na Espanha, com a parceria da Unesco, e que tratou da Educação Especial, reafirma o que já foi expresso na Declaração Mundial sobre Educação para Todos a respeito do direito da criança ao acesso e permanência na escola. A Declaração de Salamanca (UNESCO, 1994) estabeleceu que as crianças têm o direito garantido quanto à educação e, principalmente, a oportunidade de atingir a aprendizagem de acordo com o seu ritmo, pois possuem características, interesses, habilidades e necessidades de aprendizagens que lhes são únicas.

A Declaração de Salamanca associa a inserção dos indivíduos que possuem Necessidades Educativas Especiais com uma política de justiça social, ou seja:

[...] as escolas se devem ajustar a todas as crianças, independentemente das suas condições físicas, sociais, linguísticas ou outras. Neste conceito, terão de incluir-se crianças com deficiência ou sobredotados, crianças da rua ou crianças que trabaIham, crianças de populações remotas ou nômadas, crianças de minorias linguísticas, étnicas ou culturais e crianças de áreas ou grupos desfavorecidos ou marginais (UNESCO, 1994, p. 6).

O Warnock Report (WARNOCK, 1978) já se referia à necessidade de a criança ter um acompanhamento especializado de orientação e apoio, constituído por docentes especializados na maioria das escolas. Conforme a Resolução CNE/CEB n. 4/2009 (BRASIL, 2009), o Atendimento Educacional Especializado foi criado para atender os alunos da Educação Especial e, por isso, destina-se aos que possuem deficiência de natureza física, intelectual, sensorial e para os com Transtornos Globais de Desenvolvimento (TGD). ${ }^{8}$ Esse serviço, conforme a Política Nacional de Educação Especial na Perspectiva da Educação Inclusiva (BRASIL, 2008), deve ser dado em todas as etapas e modalidades de ensino como oferta complementar, favorecendo a aprendizagem dos alunos, e, por consequência disso, a escola da rede regular de ensino, necessariamente, precisa inserir e contemplar esse atendimento em seu Projeto Político-Pedagógico.

A Resolução n. 4/2009 retoma as orientações nacionais quanto ao funcionamento do Atendimento Educacional Especializado, à formação do professor desse atendimento, à intencionalidade e às garantias ao aluno com deficiência, bem como aponta a possibilidade de ter esse profissional de apoio em sala de aula. O objetivo desse atendimento aos alunos é complementar ou suplementar a formação do estudante por meio da disponibilização de serviços, recursos de acessibilidade e estratégias que eliminem as barreiras para sua plena participação na sociedade e desenvolvimento de sua aprendizagem (BRASIL, 2009).

\footnotetext{
${ }^{8}$ Este grupo é considerado o público-alvo da Educação Especial pela Política Nacional de Educação Especial na Perspectiva da Educação Inclusiva (BRASIL, 2008).
} 
Em consonância com essa Resolução, e de acordo com a Lei de Diretrizes e Bases da Educação Nacional (LDB 9.394/96), o Atendimento Educacional Especializado, assegurado no artigo $58, \S \S 1$ e $2 \circ$, deve assim proceder:

$\S 1$ 1․ Haverá, quando necessário, serviço de apoio especializado, na escola regular, para atender as peculiaridades da clientela de Educação Especial.

$\S 2$ 2․ O atendimento educacional especializado será feito em classes, escolas ou serviços especializados, sempre que, em função das condições específicas dos alunos, se não for possível a sua integração nas classes comuns de ensino regular (BRASIL, 1996).

Esse atendimento tem o objetivo de identificar, elaborar e organizar quaisquer recursos pedagógicos que possibilitem a sua acessibilidade, eliminando as barreiras para a plena participação dos alunos, considerando as suas necessidades específicas, tanto arquitetônicas quanto educacionais. Tem, ainda, o propósito de auxiliar, mediante atendimento especializado, na formação do aluno com vistas à sua autonomia e independência na escola e fora dela, e no período inverso ao da turma frequentada pelo aluno, na própria escola ou em escolas mais próximas, a fim de superar seus limites intelectuais, motores ou sensoriais.

Garcia (2008, p. 18), em seus estudos, salienta que "[...] os atendimentos especializados expressam uma concepção de inclusão escolar que considera a necessidade de identificar barreiras que impedem o acesso de alunos considerados diferentes." Há, portanto, um respeito à diversidade, permitindo o acesso e a permanência de crianças, jovens e adultos no espaço escolar e, principalmente, acesso a uma educação com qualidade. Trata-se de "[...] captar as características reais da conduta da criança em toda a sua plenitude e riqueza de expansão e apresentar o positivo de sua personalidade" (VYGOTSKY, 1995, p. 141).

As pesquisas de Carneiro e Dodge (2007) sobre as relações sociais estabelecidas pelos sujeitos, apresentam como objetivo principal a compreensão dos movimentos constitutivos das crianças no espaço escolar. Os autores propõem que todas as crianças podem e necessitam aprender a partir das interações com os demais da sala de aula, o que proporciona diferentes possibilidades de aprendizagem, como expressam:

Pensemos a aprendizagem de forma coletiva, distinta do modelo de escola que temos hoje. A abordagem histórico-cultural aponta a heterogeneidade como característica de qualquer grupo humano, sendo um fator imprescindível para as interações em sala de aula. A diversidade de experiências, trajetórias pessoais, contextos familiares, valores e níveis de conhecimento de cada membro do grupo viabiliza no cotidiano escolar a possibilidade de trocas, confrontos, ajuda mútua e consequente ampliação das capacidades individuais e coletivas (2007, p. 17).

Com isso, para que seja realizado um atendimento que venha ao encontro das necessidades e características específicas dos alunos, é preciso que o professor responsável por esse atendimento tenha formação na área da Educação Especial, conforme a Resolução do CNE/CEB n. 2/2001 (BRASIL, 2001), pois o seu desafio é o desenvolvimento de "[...] estratégias de aprendizagem, centradas em um novo saber pedagógico que 
favoreça a construção de conhecimentos pelos alunos" (ALVES, 2006, p. 13) e não de recriar um ambiente de repetições das atividades desenvolvidas em sala de aula. Nesse sentido, Xavier (2002) considera que:

[...] a construção da competência do professor para responder com qualidade às necessidades educacionais especiais de seus alunos em uma escola inclusiva, pela mediação da ética, responde à necessidade social e histórica de superação das práticas pedagógicas que discriminam, segregam e excluem, e, ao mesmo tempo, configuram, na ação educativa, o vetor de transformação social para a equidade, a solidariedade, a cidadania (p. 19).

Para tanto, de acordo com o excerto supra e em conformidade com o artigo 13 da Resolução n. 4/2009, o docente que for trabalhar na sala do atendimento educacional especializado, além de ter as atribuições descritas nessa Resolução, necessita de conhecimentos interdisciplinares para que as suas ações e práticas pedagógicas possam efetivar e garantir a inclusão escolar. Para que esse docente consiga atender toda a demanda na sala multifuncional, é necessário que tenha condições de organizar metodologias/ estratégias de ensino que atendam às especificidades dos alunos. Algumas dessas demandas estão diretamente ligadas aos conhecimentos específicos sobre

[...] Comunicação Aumentativa e Alternativa, Sistema Braille, Orientação e Mobilidade, Sorobã, Ensino de Língua Brasileira de Sinais - Libras, Ensino de Língua Portuguesa para Surdos, Atividades de Vida Diária, Atividades Cognitivas, Aprofundamento e Enriquecimento Curricular, Estimulação Precoce, entre outros (ALVES, 2006, p. 17).

Para que essas atribuições sejam possíveis de serem realizadas na prática, é imprescindível que o professor tenha acesso a uma formação inicial e continuada. De acordo com Giovanni (1994), é necessário que seja revisto e repensado o papel dos profissionais que trabalham no Atendimento Educacional Especializado, reconhecendo as suas competências ${ }^{9}$ para que possam desempenhar sua função com autonomia, entendida como um direito a ser respeitado, em relação ao seu ritmo e tempo de aprendizado.

Ainda em consonância a isso, a Educadora Especial 3 afirma que

É necessário que se efetive em todas as instituições de ensino o atendimento educacional especializado para que os alunos possam ter um atendimento que os auxilie na aprendizagem. Ainda, é necessário que os profissionais da educação estejam preparados e capacitados, buscando a sua formação contínua para dar conta do que cada criança precisa realmente durante o seu processo de ensino e de aprendizagem (ENTREVISTA, 2018).

É imprescindível que haja uma aproximação entre os profissionais que atuam nessas salas de Atendimento Educacional Especializado e daqueles que atuam no ensino regular, a fim de que aconteçam trocas de saberes e experiências que proporcionem a aprendizagem dos alunos incluídos. É sabido que compete ao professor da sala de aula

\footnotetext{
${ }^{9}$ De acordo com Perrenoud (2002, p. 7), a competência é a "capacidade de agir eficazmente em um determinado tipo de situação, apoiada em conhecimentos, mas sem limitar-se a eles." 
da escola regular a tarefa de ensinar o conteúdo das áreas do conhecimento e, ao professor das salas multifuncionais, auxiliar nesse processo de aprendizagem e apreensão de conteúdos de forma complementar e/ou suplementar, com o uso de recursos específicos que propiciem a autonomia e a independência na participação de suas atividades.

Para que o aluno tenha êxito em suas atividades, é necessário compreender que não pode haver um planejamento estático ou ações predefinidas, mesmo considerando que alguns desses alunos possuem as mesmas deficiências. É preciso ter consciência que cada criança possui desenvolvimento e necessidades diferentes de cuidado na organização para que efetivamente ocorra uma aprendizagem de qualidade. Assim sendo, além de ter um diagnóstico em suas mãos, o profissional do atendimento educacional especializado precisa conhecer a história de vida do seu aluno, suas particularidades, seus desejos e diferenças, para que possa traçar um planejamento/caminho para auxiliar nesse processo de aprendizagem.

Assim, de acordo com Mazzotta (2008),

Não podemos nos esquecer de que há situações escolares que podem requerer significativas intervenções e recursos diferenciados ou mesmo especializados para atender apropriadamente às necessidades educacionais de alguns alunos. $E$, para demandas educacionais escolares muito diferenciadas, das que frequentemente se apresentam, são esperadas providências, medidas e recursos educacionais escolares diferenciados ou especiais em relação àqueles que já se encontram estruturados e disponíveis para utilização (p. 167).

Vygotsky (2008) enfatiza que o aprendizado é necessário para o desenvolvimento das funções psicológicas superiores. Destaca-se a cultura e as formas de interação com o meio e com os outros seres humanos como aspecto fundamental no desenvolvimento dos processos psicológicos superiores dos seres humanos, assim como a capacidade humana de conhecer e atuar no mundo em que se vive, pois são produções sociais que dependem das relações que os seres humanos precisam estabelecer com o meio em que vivem.

A partir das ideias deste autor, entende-se que o trabalho desenvolvido nas salas multifuncionais precisa estar voltado ao atendimento das necessidades dos alunos incluídos. Nesse pensamento, o Modelo Social propõe uma perspectiva que valoriza o ser humano, o sujeito, vindo a romper as concepções sobre a deficiência em uma visão clínica, valorizando as suas habilidades e potencialidades durante o seu processo de aprendizagem.

A avaliação desses alunos, quando em atendimento nessas salas multifuncionais, deve ter um caráter contínuo, atendendo às suas necessidades educativas. $O$ docente dessas salas e das salas do ensino regular necessitará estar ciente de que os processos avaliativos deverão ter o compromisso de realizar um trabalho em conjunto, a fim de realizar práticas pedagógicas em sala de aula "de maneira que possa a vir valorizar os conhecimentos que o aluno já tenha alcançado ou ainda necessita alcançar" (ENTREVISTA, EDUCADORA ESPECIAL 2, 2018). Nessa perspectiva, de olhar o aluno em seu desenvolvimento, valorizando a sua condição social, Gentilli (2009) enfatiza que a inclusão na educação é um direito humano e se constitui em uma ação social, pois 
[...] supôs o reconhecimento de uma série de questões associadas e indissoluvelmente unidas a esse direito [...]. O fato incontestável é que a afirmação do direito à educação, como um direito humano fundamental, estava associada ao reconhecimento das condições indispensáveis para a construção de uma sociedade mais justa e igualitária (p. 6).

Para que a inclusão aconteça efetivamente em todos os setores da sociedade, mais precisamente nos espaços em que acontecem os processos de ensino e de aprendizagem, que é direito de todo o cidadão, é necessário que haja, urgentemente, uma mudança de paradigmas de uma educação padronizada na compreensão e aceitação do outro, sobre as suas especificidades e diferenças. Para a professora 2, "é urgente que todos nós, profissionais da educação, busquemos formações específicas em todas as áreas, deficiência auditiva, visual, TGD, entre tantas outras, para aprimorar os nossos conhecimentos, a fim de podermos ser intermediadores no processo de ensino e de aprendizagem" (ENTREVISTA, PROFESSORA 2, 2018), pois somente diante dessa mudança poderá haver a possibilidade de favorecer um espaço que venha a potencializar um ambiente de aprendizagem.

Desse modo, é no contexto social que as diferenças são explicitadas e adquiridas de forma a acarretar dificuldades para o sujeito interagir com o meio social e físico. Para a Monitora da Escola 1, "a criança necessita estar dentro do espaço escolar interagindo com as outras crianças para poder compartilhar e produzir novos conhecimentos" (ENTREVISTA, MONITORA 1, 2018). Carvalho $(2008$, p. 98) defende que a proposta inclusiva deva favorecer uma escola de qualidade para todos, que não segregue, que não roube e não 'expulse' alunos com 'problemas', mas que favoreça uma escola que enfrente problemas como o fracasso e evasão escolar, atendendo as necessidades dos alunos.

Nessa mesma perspectiva, para Ferreira (2005, p. 44), a inclusão numa escola que pense as diferenças e as respeite, necessariamente envolve "[...] uma filosofia que valoriza diversidade de força, habilidades e necessidades [do ser humano] como natural e desejável", trazendo para cada comunidade a oportunidade de responder de forma que conduza à aprendizagem e ao crescimento da comunidade como um todo, e dando a cada membro desta comunidade um papel de valor.

Com base em Vygotsky (2003), compreende-se que as atividades e situações de aprendizagem desenvolvidas em sala de aula devem se consolidar na qualidade das experiências criadas pelo grupo em um momento social, quando a criança pode configurar a sua aprendizagem de modo qualitativo. Vygotsky (2002), em seus estudos sobre o desenvolvimento, educação e deficiência dos sujeitos, alerta sobre a importância de a criança ter uma vida social, o que está intrinsecamente presente no desenvolvimento humano. $\mathrm{O}$ autor, ainda de acordo com as educadoras especiais, afirma que crianças com necessidades específicas necessitam de condições que atendam às peculiaridades individuais, e que o respeito a essas diferenças pode permitir a inserção em uma vida coletiva. 
Para tanto, ao conceituar a Educação Inclusiva ante a uma interação completa em sala de aula, onde terão as suas necessidades atendidas, privilegiando a socialização e a constante construção do conhecimento, remete-se a um cenário educacional que propicia momentos de construção de conhecimentos no coletivo, como explicita Mittler (2003):

No campo da educação, a inclusão envolve um processo de reforma e de reestruturação das escolas como um todo, com o objetivo de assegurar que todos os alunos possam ter acesso a todas as gamas de oportunidades educacionais e sociais oferecidas pela escola (p. 25).

Não se pretende, com isso, negar as suas dificuldades ou necessidades, mas possibilitar o seu desenvolvimento, respeitando o seu ritmo em um convívio social com seus pares. Nessa perspectiva, pode-se assegurar que os autores citados no aporte teórico deste estudo, defendem a necessidade de mudança na concepção da deficiência dos familiares e profissionais da Educação sobre o tema, numa perspectiva de Modelo Social, respeitando e propiciando uma aprendizagem de acordo com o ritmo de cada um. Ainda, de forma muito específica, que o educador da sala multifuncional e da sala regular tenham uma prática pedagógica que possa auxiliar a aprendizagem dos sujeitos envolvidos.

Souza (2009) apresenta a prática pedagógica como prática social, com caráter especificamente histórico e cultural, que vai muito além das práticas utilizadas em sala de aula pelo docente, envolvendo as atividades didáticas e suas relações com a comunidade e sociedade. Assim, toda a prática pedagógica ultrapassa os espaços da sala de aula e das instituições de ensino, tendo em vista a formação humana do sujeito. $O$ autor ressalta, ainda, que toda e qualquer prática pedagógica não pode ser considerada uma única instância responsável pela formação de professor:

A prática pedagógica que objetiva a formação de professor é importante, mas não é a única nem decisiva para essa formação. Ela legaliza e legitima o exercício profissional, repito, mas não é a única nem decisiva no processo de transformar alguém em um professor (SOUZA, 2009, p. 23).

O autor supracitado ainda assevera que a prática social está intrinsicamente associada à prática pedagógica dos profissionais da Educação, e que, dessa forma, a

[...] inter-relação de práticas de sujeitos sociais formadores que objetivam a formação de sujeitos que desejam ser educados (sujeitos em formação) respondendo aos requerimentos de uma determinada sociedade em um momento determinado de sua história, produzindo conhecimentos que ajudem a compreender e atuar nessa mesma sociedade e na realização humana dos seus sujeitos [...]. (p. 29).

Assim, toda prática educativa inerente à prática pedagógica é reflexiva e, com isso, marca as relações interativas que os sujeitos mantêm na sociedade. Diante disso, pode-se considerar que toda a prática pedagógica é um exercício inter-relacionado entre teoria e prática e, com isso, a prática pedagógica é essencialmente humana, direcionada e intencionada. 


\section{ALGUMAS REFLEXÕES}

Ao propor esse debate sobre essas questões tão recorrentes, acreditamos que as diversas contribuições dos protagonistas de nossa pesquisa em formato de entrevistas semiestruturadas dos discursos e das práticas observadas em escolas municipais, nos permitiram ir além da questão e perceber que é necessário uma reestruturação da formação docente, abordando questões teóricas que sejam recorrentes para uma efetiva transformação da prática em todos os espaços da escola.

No âmbito dos atravessamentos e das contradições sobre a educação inclusiva e o Atendimento Educacional Especializado, fundamentados na perspectiva histórica e cultural, identificamos muitos aspectos favoráveis ao processo de inclusão nesses espaços institucionais. Dessa forma, é inevitável que os professores, a partir da teoria abordada, assumam o seu papel de intermediadores da aprendizagem dos alunos e, assim, possam desenvolver práticas potencialmente eficazes e com qualidade na promoção efetiva do processo inclusivo.

Além disso, podemos apontar para as possibilidades e necessidade de reorganização de programas que ofereçam uma formação continuada para que esses educadores possam se instrumentalizar e atuar junto as turmas de estudantes, público-alvo da educação especial, atendendo à singularidade de cada um e auxiliando a superar as dificuldades que possam vir a surgir.

\section{REFERÊNCIAS}

ARANHA, M. S. F. Paradigmas da relação da sociedade com as pessoas com deficiência. Revista do Ministério Público do Trabalho, v. XI, n. 21, 2001.

ALVES, D. O. Sala de recursos multifuncionais: espaços para atendimento educacional especializado. Brasília, DF: Ministério da Educação; Secretaria de Educação Especial, 2006.

BAMPI, L. N. S.; GUILHEM, D.; ALVES, E. D. Modelo social: uma nova abordagem para o tema deficiência. Revista Latino-Americana de Enfermagem, v. 18, n. 4, jul./ago. 2010. Disponível em: http://www.scielo. $\mathrm{br} / \mathrm{pdf} / \mathrm{rlae} / \mathrm{v18n4/pt} 22 . p d f$. Acesso em: 10 jun. 2017.

BARDIN, L. Análise de conteúdo. São Paulo: Edições 70, 2011.

BARNES, C.; MENCER, G. Introduction: exploring the divide. Exploring the divide: illness and disability. Leeds: Disability Press, 1996.

BATISTA, C. A. M. Educação inclusiva: atendimento educacional especializado para a deficiência mental. Brasília: MEC; SEESP, 2006.

BRASIL. Ministério da Educação. Secretaria de Educação Especial. Política Nacional de Educação Especial na Perspectiva da Educação Inclusiva. Brasília, DF, 2008. Disponível em: http://portal.mec.gov.br/arquivos/pdf/politicaeduc especial. pdf. Acesso em: 12 maio 2017.

BRASIL. Resolução CNE/CEB no 04/2009. Diretrizes Operacionais para o Atendimento Educacional Especializado na Educação Básica. Disponível em: http://portal.mec.gov.br/dmdocuments/rceb004_09.pdf. Acesso em: 17 dez. 2017.

BRASIL. Resolução no 2, de 11 de setembro de 2001. Institui Diretrizes Nacionais para a Educação Especial na Educação Básica. Brasília: MEC/CNE/CEB, 2001. Disponível em: http://portal.mec.gov.br/cne/arquivos/pdf/CEB0201.pdf. Acesso em: 5 out. 2017.

BRASIL. Decreto no 5.626, de 22 de dezembro de 2005. Regulamenta a Lei $n^{\circ} 10.436$, de 24 de abril de 2002, que dispõe sobre a Língua Brasileira de Sinais - Libras, e o art. 18 da Lei no 10.098, de 19 de dezembro de 2000. Brasília: Senado Federal, 2005. Disponível em: http://www.planalto.gov.br/ccivil_03/_ ato2004-2006/2005/decreto/d5626.htm. Acesso em: 5 out. 2017.

BRASIL. Resolução no 510, de 7 de abril de 2016. Ministério da Saúde. Conselho Nacional de Saúde. Disponível em: http://conselho.saude.gov.br/resolucoes/2016/Reso510.pdf. Acesso em: 13 jul. 2017. 
BRASIL. Lei no 10.436, de 24 de abril de 2002. Dispõe sobre a Língua Brasileira de Sinais - Libras e dá outras providências. Brasília: Senado Federal, 2002. Disponível em: http://portal.mec.gov.br/ arquivos/pdf/ lei10436.pdf. Acesso em: 27 ago. 2017.

BRASIL. Lei no 9.394, de 20 de dezembro de 1996. Estabelece as Diretrizes e Bases da Educação Nacional. Diário oficial [da] República Federativa do Brasil, Brasília, DF, 23 dez. 1996. Disponível em: http://www. planalto.gov.br/ccivil_03/leis/19394.htm. Acesso em: 23 set. 2017.

BUENO, J. G. S. Educação especial brasileira: integração/segregação do aluno diferente. São Paulo: Educ, 1993.

CARNEIRO, M. A. B.; DODGE, J. J. A descoberta do brincar. São Paulo: Melhoramentos, 2007.

CARVALHO, R. E. Escola inclusiva: a reorganização do trabalho pedagógico. Porto Alegre: Mediação, 2008. CARVALHO, M. F. Conhecimento e vida na escola: convivendo com as diferenças. Campinas: Autores Associados, 2006.

DINIZ, D. O modelo social da deficiência: a crítica feminista. Brasília: Letras Livres, 2003 (Série Anis, 28). Disponível em: https://repositorio.ufsc.br/xmlui/bitstream/handle/123456789/1239/diniz_debora.pdf?sequence=1\&isAllowed=y. Acesso em: 10 jun. 2017

DINIZ, D. O que é deficiência. São Paulo: Brasiliense, 2007. (Coleção Primeiros Passos, 324).

FERREIRA, W. B. Educação inclusiva: será que sou a favor ou contra uma escola de qualidade para todos? Revista da Educação Especial , n. 40, out. 2005.

FREDERICK, K. "Let's take the special out of special needs" in Times Educational Supplement. 2005. Disponível em: https://www.tes.com/news/tes-archive/tes-publication/lets-take-special-out-special-needs. Acesso em: 8 jun. 2017.

FIORINI, M. L. S. Concepção do professor de Educação Física sobre a inclusão do aluno com deficiência. 2011, 143f. Dissertação (Mestrado em Educação) - Universidade Estadual Paulista, Faculdade de Filosofia e Ciências, Marília, 2011.

FOGLI, B. F. C. S. A dialética da inclusão em educação: uma possibilidade em um cenário de contradições - "um estudo de caso sobre a implementação de inclusão para alunos com deficiências na rede de ensino Faetec, 2010, 173f. Disponível em: http://www.eduinclusivapesq-uerj.pro.br/images/pdf/BiancaFogli_Tese_2010.pdf. Acesso em: 24 jan. 2018.

FRANÇA, T. H. Modelo social da deficiência: uma ferramenta sociológica para a emancipação social. $R e-$ vista Lutas Sociais, São Paulo, v. 17, n. 31, p. 59-73, 2013. Disponível em: https://revistas.pucsp.br/index. php/Is/article/view/25723. Acesso em: 23 abr. 2019.

GARCIA, R. M. C. Políticas inclusivas na educação: do global ao local. In: BAPTISTA, C. R.; CAIADO, K. R. M.; JESUS, D. M. (org.). Educação especial: diálogo e pluralidade. Porto Alegre: Mediação, 2008.

GENTILLI, P. O direito à educação e as dinâmicas de exclusão na América Latina. Educação e Sociedade. Campinas, SP, set./dez. 2009.

GIOVANNI, L. M. Aprendendo sobre a profissão docente com o exercício da liberdade para refletir. São Paulo: Araraquara, 1994.

GÓES, M. C. R. Linguagem, surdez e educação. Campinas, SP: Autores Associados, 1996.

HUNT, Paul. Stigma: the experience of disability. London: Geoffrey Chapman, 1966.

IZQUIERDO, T. M. R. Necessidades educativas especiais: a mudança pelo Relatório Warnock. 2006. Dissertação (Mestrado) - Universidade de Aveiro, 2006. Disponível em: http://ria.ua.pt/handle/10773/995. Acesso em: 27 jun. 2017.

LINO DE PAULA, L. A. Ética e educação especial: uma reflexão sobre a cidadania do portador de deficiência mental. 1994. Dissertação (Mestrado em Educação) - Universidade Estadual do Rio de Janeiro - Uerj, Rio de Janeiro, 1994.

MANTOAN, M. T. E. O direito à diferença nas escolas. Pátio, ano VIII, n. 32, p. 13-15, 2005.

MARQUES, S. M. Pensar e agir na inclusão escolar de crianças com necessidades educacionais especiais decorrentes de uma deficiência, a partir de referenciais freirianos: rupturas e mutações culturais na escola brasileira. 2007. 344f. Tese (Doutorado) - Faculdade de Educação, Universidade de São Paulo, São Paulo, 2007.

MAZZOTTA, M. J. S. Trabalho docente e formação de professores de Educação Especial. São Paulo: EPU, 1993.

MAZZOTTA, M. J. S. Educação especial no Brasil. São Paulo: Cortez, 1996.

MAZZOTTA, M. J. S. Reflexões sobre inclusão com responsabilidade. Revista @mbienteeducação, São Paulo, v. 1, n. ${ }^{\circ}$ 2, p. 165-168, ago./dez. 2008. 
MENDES, E. G. Perspectivas para a construção da escola inclusiva no Brasil. In: PALHARES, M.; MARINS, S. (org.). Escola inclusiva. São Carlos: EdUFSCar, 2002. p. 61-85.

MINAYO, M. C. S. Ciência, técnica e arte: o desafio da pesquisa social. In: MINAYO, M. C. S. (org.). Pesquisa social: teoria, método e criatividade. 18. ed. Petrópolis, RJ: Vozes, 1999. p. 9-29.

MITTLER, P. Educação inclusiva: contextos sociais. Porto Alegre: Artmed, 2003.

MOURA, M. C. História e educação: o surdo, a oralidade e o uso de sinais. In: LOPES FILHO, O. C. (org.). Tratado de fonoaudiologia. São Paulo: Rocca, 1997.

PERRENOUD, P. A prática reflexiva no ofício do professor: profissionalização e razão pedagógica. Porto Alegre: Artmed, 2002.

PESSOTTI, I. Deficiência mental: da superstição à ciência. São Paulo: T.A. Queiroz, 1984.

PEREIRA, E. C. Os processos formativos do professor de alunos com Transtorno do Espectro Autista: contribuições da Teoria Histórico-Cultural. 2016. 191f. Dissertação (Mestrado em Educação) - Faculdade de Educação, Universidade de São Paulo, São Paulo, 2016.

PAULA, J. Inclusão: mais que um desafio escolar, um desafio social. São Paulo: Jairo de Paula, 2004.

RAMPELOTTO, E. M. A invenção da educação especial. Revista Educação Especial, Santa Maria, RS, n. 24, p. 53-64, 2004. Disponível em: https://periodicos. ufsm.br/educacaoespecial/article/view/4915. Acesso em: 22 mar. 2019.

ROCHA, S. Histórico do Ines. Revista Espaço: edição comemorativa 140 anos. Instituto Nacional de Educação de Surdos (Ines). Belo Horizonte: Líttera, 1997.

SACKS, O. Vendo vozes: uma viagem ao mundo dos surdos. Trad. Laura Teixeira Motta. São Paulo: Companhia das Letras, 1998.

SASSAKI, R. K. Como chamar as pessoas que têm deficiência. São Paulo: RNR, 2002. Disponível em: http:// sivc.saci.org.br/files/chamar.pdf. Acesso em: 29 jun. 2017.

SKLIAR, C. B.; SOUZA, R. M. O debate sobre as diferenças e os caminhos para (re) pensar a educação. In: AZEVEDO, J. C.; GENTILI, P.; KRUG, A.; SIMON, C. (org.). Utopia e democracia na educação cidadã. Porto Alegre: Secretaria Municipal da Educação de Porto Alegre, 2000.

SKLIAR, C. B.; SOUZA, R. M. A invenção e a exclusão da alteridade "deficiente" a partir dos significados da normalidade. Educação e Realidade, Porto Alegre, v. 24, n. 2, jul./dez. 1999.

STAINBACK, S.; STAINBACK, W. Inclusão: um guia para educadores. Trad. Magda França Lopes. Porto Alegre: Artes Médicas, 1999.

STROBEL, Karin. História da educação de surdos. Universidade Federal de Santa Catarina, 2009. Disponível em: http://www.libras.ufsc.br/colecaoLetrasLibras/eixo FormacaoEspecifica/historiaDaEducacaoDeSurdos/assets/258/TextoBase_HistoriaEducacaoSurdos.pdf. Acesso em: 27 maio 2017.

SOARES, M. A. L. A educação do surdo no Brasil. Campinas, SP: Autores Associados; Edusf, 1999.

SOUZA, J. F. Prática pedagógica e formação de professores. In: BATISTA NETO, J.; SANTIAGO, E. (org.). Prática pedagógica e formação de professores. Recife: Edufpe, 2009.

UNESCO. Organização das Nações Unidas para a Educação, Ciência e Cultura. Declaração de Salamanca e Linha de Ação sobre Necessidades Educativas Especiais. Brasília: Corde, 1994. Disponível em: www.portal. mec.gov.br/seesp/arquivos/pdf/salamanca.pdf. Acesso em: 15 mar. 2017.

VYGOTSKY, L. S. A formação social da mente: o desenvolvimento dos processos psicológicos superiores. 6. ed. São Paulo: Martins Fontes, 2002.

VYGOTSKY, L. S. Psicologia pedagógica. Porto Alegre: Artmed, 2003.

VYGOTSKY, L. S. Pensamento e linguagem. São Paulo: Martins Fontes, 2008.

VYGOTSKY, L. S. Obras escogidas I: problemas teóricos y metodológicos de la psicología. Trad. José Maria Bravo. 2. ed. Madrid: Visor Dist., 1989, 1995, 1997, 1997a, 1997b, tomo I.

WARNOCK, M. Pamphlet "Special educational needs: a new look". № 11 in a series of policy discussions. Published by the Philosophy of Education Society of Great Britain, 1978.

WERNECK, C. Modelo médico x Modelo social da deficiência. Manual da mídia legal 3: comunicadores pela saúde. Escola de Gente. Rio de Janeiro: WVA, 2004. p. 16-20.

XAVIER, A. G. P. Ética, técnica e política: a competência docente na proposta inclusiva. Revista Integração, Brasília, v. 14, n. 24, 2002. 